\title{
Incidence of hypertension in a prospective cohort study of adults from Porto, Portugal
}

\author{
Marta Pereira ${ }^{1 *}$, Nuno Lunet ${ }^{2}$, Cristiana Paulo ${ }^{3}$, Milton Severo ${ }^{4}$, Ana Azevedo ${ }^{5}$ and Henrique Barros ${ }^{6}$
}

\begin{abstract}
Background: During the past 30 years, Portugal has been described as one of the countries with highest median blood pressure levels in Europe, but the incidence of hypertension is unknown. The aim of this study was to estimate the incidence of hypertension, according to socio-demographic characteristics and lifestyles.

Methods: A population-based cohort of randomly selected dwellers from Porto, Portugal, aged $\geq 18$ years, was assembled in 1999-2003 (EPIPorto study) and 796 hypertension-free individuals (62.6\% women) were reassessed after a median of 3.8 years. Hypertension was defined as blood pressure $\geq 140 / 90 \mathrm{mmHg}$ and/or antihypertensive drug therapy. Incidence rate ratios (IRR) were estimated using Poisson regression.

Results: The overall incidence rate was 47.3 [95\% confidence interval (95\% Cl): 40.5-55.5] per 1000 person-years. Among women, the incidence was 43.4 (35.6-53.1) and among men 52.7 (41.3-68.0) per 1000 person-years. The incidence was lower in women up to 60 years and much higher among women above 60 (110.0 vs. 64.4 per 1000 person-years among men, $\mathrm{p}$ for age-sex interaction $=0.032$ ). Participants with higher education had a lower risk of becoming hypertensive ( $\geq 13$ years vs. $\leq 4$ years: $R R=0.70,95 \% \mathrm{Cl}, 0.46-1.08$, $\mathrm{p}$ for linear trend $<0.001$ ), independently of age and sex. Overweight and obesity were associated with a 1.67-fold and 2.44-fold increased risk of hypertension, respectively, independently of age, sex and education.

Conclusions: In this urban Portuguese population the incidence rate of hypertension was high, with new cases occurring predominantly among older subjects, the less educated and those with overweight-obesity. Despite recent progresses in blood pressure related outcomes, the risk of hypertension remains higher in Portugal than in other developed countries.
\end{abstract}

Keywords: Adults, Hypertension, Incidence, Portugal

\section{Background}

Hypertension is a modifiable risk factor responsible for a high burden of disability and death $[1,2]$. Beyond genetic susceptibility, environmental factors change the severity of blood pressure elevation and the timing of hypertension onset $[3,4]$. There is a high lifetime risk of hypertension, which is sustained after middle age. In the Framingham Heart Study, the residual lifetime risk of hypertension for middle-aged and elderly individuals was $90 \%$, and more than half of 55 -year-old participants and about two thirds of 65-year-old participants developed hypertension within 10 years [5].

\footnotetext{
* Correspondence: martasfp@med.up.pt

'Department of Clinical Epidemiology, Predictive Medicine \& Public Health, Institute of Public Health of the University of Porto (ISPUP), University of Porto Medical School, Porto, Portugal

Full list of author information is available at the end of the article
}

In Portugal, where stroke has been the leading cause of death for decades, hypertension is a highly prevalent condition [6,7]. According to two population-based studies in the early 2000s, describing the adult population of mainland Portugal [7] and of Porto [8], the prevalence of hypertension was approximately $40 \%$. The prevalence of self-reported hypertension has been increasing in Portugal for over two decades [9]. However, this can result from higher diagnostic sensitivity, or a higher awareness of providers or patients, since mean blood pressure levels have been decreasing for at least 30 years and the prevalence of hypertension, objectively defined by high blood pressure levels or being under antihypertensive treatment, is stable in younger ages and decreasing in older people [9]. 
Despite its usefulness as a measure of the burden of disease, the prevalence of hypertension is largely determined by the proportion of subjects under treatment and longer duration of cases [10]. On the other hand, hypertension incidence, although influenced by the access of the population to diagnosis, reflects more closely the scope for primary prevention, since it represents the rate of occurrence of new cases. However, population health data seldom provide such information.

Thus, we aimed to quantify the incidence of hypertension in adults, based on the prospective study of a community cohort of Porto, Portugal inhabitants, and to compare rates according to socio-demographic and behavioural characteristics.

\section{Methods}

A cohort of 2485 adult dwellers in Porto, an urban center in the northwest of Portugal with almost 300,000 inhabitants at that time, was assembled between 1999 and 2003 [8,11]. Briefly, simple random digit dialing of landline telephones was used to select households. The vast majority of houses (>95\%) had a landline telephone at the time of this procedure. We used a table of random numbers to define the last four digits that are specific to individual houses, assuming the local prefix codes to limit the universe to the city of Porto. Non-existing numbers, those corresponding to fax numbers or telephone numbers of non-individual subscribers were ignored. The household was considered unreachable after at least four dialing attempts at different hours and including week and weekend days. Within each household, we selected a permanent resident aged 18 years or more using simple random sampling. We considered a refusal if the person explicitly said that she did not want to participate and refusals were not substituted within the same household. The proportion of participation was $70 \%$ [12]. A follow-up evaluation was conducted from 2005 to 2008, by trained interviewers, using structured questionnaires and forms, following the same protocol for data collection as at baseline. In both evaluations, participants were invited to visit our Department for an interview, which included a questionnaire on social, demographic, behavioural and clinical data, and a physical examination, including measurement of weight, height and blood pressure.

Age was categorized in 3 groups: <40, 40-60, 60 years or more. Education was recorded as completed years of schooling and subjects divided into three categories: $\leq 4$, 5-12 and $\geq 13$ years. Marital status was self-reported and grouped into two classes: married or in a civil union and single, widowed or divorced/separated.

We considered current smokers those who reported to smoke daily (at least one cigarette per day at the time of the survey) or occasionally (less than a cigarette per day) and ex-smokers those who had stopped smoking for at least 6 months. Average lifetime alcohol consumption, considering duration, frequency, and amount consumed by type of alcoholic beverage (wine, beer, spirits and liquors) was assessed using a questionnaire. A photographic album was used to assist in the report of the average size of the drinks. The daily intake of ethanol (g/day) was estimated by multiplying the quantity and frequency of intake of each drink by its alcohol content. Classes of alcohol consumption were defined by the cut-off points $15.0 \mathrm{~g} /$ day for women and $30.0 \mathrm{~g} /$ day for men, according to the recommendations of the American Heart Association [13].

Physical activity was evaluated using a previously validated questionnaire [14] exploring all professional, domestic and leisure-time activities, detailing the intensity, duration and frequency of each activity. We used metabolic equivalents (MET), defined as the ratio between the metabolic rate during a specific physical activity and a reference metabolic rate, to quantify the intensity of each activity. The intensity of each activity was then multiplied by its frequency and duration to obtain the amount of physical activity measured as MET*hour/day. The subjects were then classified according to the sex-specific tertiles of the sample distribution.

Anthropometric measurements were performed after an overnight fast, with the participant wearing light clothing and no footwear. Body weight was measured to the nearest $0.1 \mathrm{~kg}$ using a digital scale, and height was measured to the nearest centimeter in the standing position using a wall stadiometer. Body mass index (BMI) was calculated as weight $(\mathrm{kg})$ divided by squared height $\left(\mathrm{m}^{2}\right)$ and subjects categorized according to the recommendations of the World Health Organization: obese $\left(\geq 30 \mathrm{~kg} / \mathrm{m}^{2}\right)$, overweight $\left(25.0-29.9 \mathrm{~kg} / \mathrm{m}^{2}\right)$, normal $\left(18.5-24.9 \mathrm{~kg} / \mathrm{m}^{2}\right)$ and underweight $\left(<18.5 \mathrm{~kg} / \mathrm{m}^{2}\right)[15]$. The small number of underweight participants in this study did not allow accurate inferences about this group and therefore this category was grouped with normal weight.

Blood pressure measurements were performed according to the recommendations of the American Heart Association valid at the time of data collection [16]. Participants were instructed to take their usual medication and restrain from alcohol, tea, coffee, smoking or practise exercise in the 30 minutes preceding the measurement. Systolic blood pressure was identified by phase I Korotkoff sound and diastolic blood pressure by phase V. Two measurements of blood pressure separated by at least 5 minutes were taken, on a single occasion, with a mercury sphygmomanometer after 10-minute rest, with no tight clothes, on the right upper arm and at the heart level. The mean was considered and when the difference was larger than $5 \mathrm{mmHg}$ for systolic or diastolic blood 
pressure a third measurement was taken and the mean of the 2 closest values was registered. The average of the readings was used to classify participants into one of the blood pressure categories of the 2007 Guidelines for the Management of Arterial Hypertension of the European Society of Hypertension and the European Society of Cardiology: optimal (systolic $<120 \mathrm{mmHg}$ and diastolic $<80 \mathrm{mmHg}$ ), normal (systolic 120-129 $\mathrm{mmHg}$ or diastolic 80-84 mmHg), high normal blood pressure (systolic $130-139 \mathrm{mmHg}$ or diastolic $85-89 \mathrm{mmHg}$ ) [17]. Arterial hypertension was defined as systolic blood pressure $\geq 140 \mathrm{mmHg}$ and/or diastolic blood pressure $\geq 90 \mathrm{mmHg}$ and/or current antihypertensive drug therapy $[17,18]$. Blood pressure was measured following the same technical procedures at baseline and follow-up assessments.

Among the 2485 individuals evaluated at baseline, 1366 were not eligible for the present study due to missing information on blood pressure $(n=176)$ or prevalent hypertension at baseline $(n=1190)$. From the remaining 1119 individuals considered for the present longitudinal analysis, 320 did not attend the complete follow-up evaluation (Figure 1). Three participants had missing data on blood pressure at follow-up. Participants with available data from the follow-up visit were more likely to be older, to be married or in civil union, less likely to be current smokers and more likely to have high normal blood pressure at baseline (Table 1).

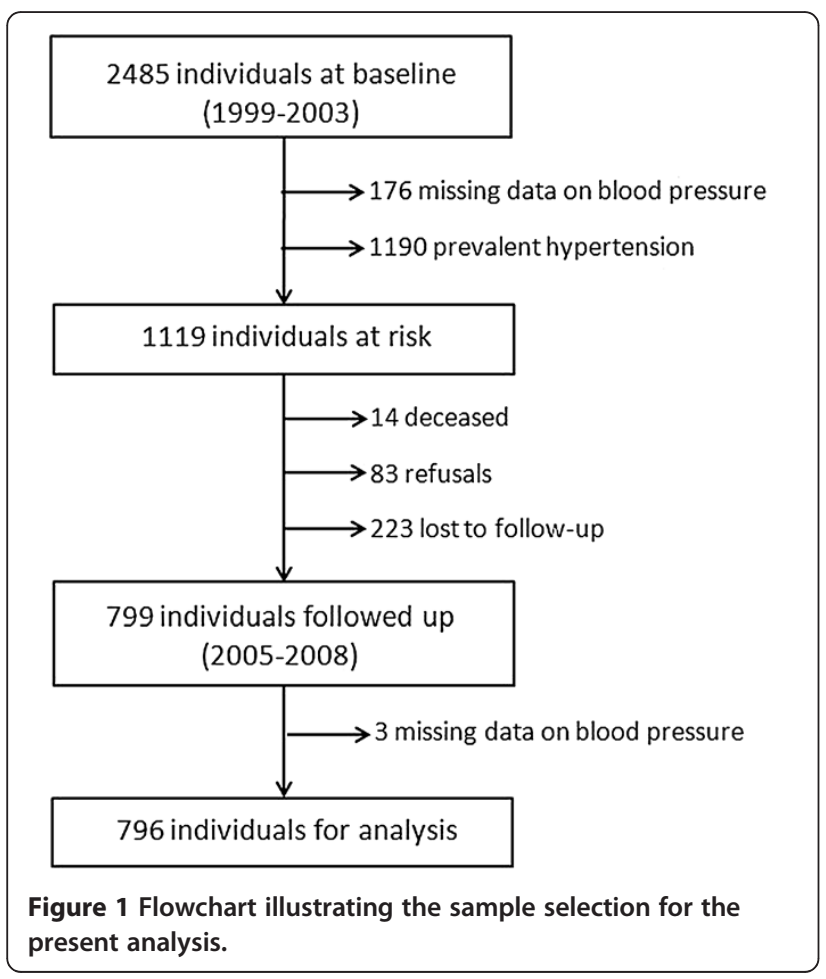

Among the 796 respondents, 62.6\% were women, the median schooling was 11 years and one quarter did not complete more than elementary school, $12 \%$ were obese, most were sedentary and the median level of total physical activity was $1.47 \mathrm{MET}$ *hour/day. The median ethanol intake was $26.3 \mathrm{~g} /$ day among men and $1.4 \mathrm{~g} /$ day among women, with 197 (41.7\%) women reporting no alcohol intake at all.

\section{Statistical analysis}

The incidence rate was computed as the number of new cases of hypertension over the total person-time at risk. Time at risk was counted as the time between the two evaluations for subjects who remained free of hypertension; in 123 new cases of hypertension (excluding those who started antihypertensive drugs) time at risk was extrapolated by the proportional variation of blood pressure, assuming this variation was linear in time, and for the 62 individuals who were started on antihypertensive drugs the medium time between the two evaluations was assumed as the date of onset. We used this methodology to take into account that those with higher baseline blood pressure have a higher probability of becoming hypertensive for a given time period. The median (interquartile range) of the follow-up period was 3.8 (2.4-6.4) years.

Poisson regression was used to compute relative risks (RR) and respective 95\% confidence intervals (95\% CI) to quantify the association between explanatory variables and hypertension incidence. The possible interaction of each of the other explanatory variables with age was tested. Crude and sex-, age- and education-adjusted RR were estimated, considering the interaction that was documented between sex and age. All analyses were weighted according to the known age and gender structure of the population of Porto, obtained from census data in 2001, to attain estimates generalizable to this population. The statistical analysis was performed using Stata version $9^{\circledR}$ (Stata Corporation, College Station, Texas, USA).

\section{Ethics}

The ethics committee "Comissão de Ética para a Saúde" of Hospital de São João approved the study and participants provided written informed consent.

\section{Results}

During the follow-up period, 185 individuals developed hypertension, corresponding to an overall incidence rate of 47.3 (40.5-55.5) per 1000 person-years. Among women, the incidence rate was 43.4 (35.6-53.1) per 1000 personyears and among men 52.7 (41.3-68.0) per 1000 personyears. Although the incidence rate increased with age similarly in both sexes up to 60 years, with the rate being lower in women, in older participants the incidence rate 
Table 1 Comparison of the participants with and without available data, among those eligible for the analysis

\begin{tabular}{|c|c|c|c|}
\hline & With available data $\mathrm{N}=796 \mathrm{n}(\%)$ & Without available data $\mathrm{N}=323 \mathrm{n}(\%)$ & $P$ value \\
\hline Female gender & $498(62.6)$ & $214(66.2)$ & 0.245 \\
\hline \multicolumn{4}{|l|}{ Age (years) } \\
\hline$<40$ & $255(32.0)$ & $140(43.3)$ & \multirow[t]{3}{*}{0.001} \\
\hline $40-60$ & $433(54.4)$ & $141(43.6)$ & \\
\hline$\geq 60$ & 108 (13.6) & $42(13.0)$ & \\
\hline \multicolumn{4}{|l|}{ Education } \\
\hline$\leq 4$ & $194(24.4)$ & $86(26.6)$ & \multirow[t]{3}{*}{0.552} \\
\hline $4-12$ & $300(37.7)$ & $125(38.7)$ & \\
\hline$\geq 13$ & $302(37.9)$ & $112(34.7)$ & \\
\hline Married/civil union & $533(67.0)$ & $195(60.6)$ & 0.042 \\
\hline \multicolumn{4}{|l|}{ Tobacco consumption } \\
\hline current smoker & $242(30.5)$ & $124(39.0)$ & \multirow[t]{3}{*}{0.019} \\
\hline ex-smoker & $151(19.0)$ & $48(15.1)$ & \\
\hline never-smokers & $401(50.5)$ & $146(45.9)$ & \\
\hline $\begin{array}{l}\text { Ethanol intake } \geq 15.0 \mathrm{~g} / \text { day (women) or } \geq 30.0 \mathrm{~g} / \text { day } \\
\text { (men) }\end{array}$ & $193(26.1)$ & $67(23.2)$ & 0.331 \\
\hline \multicolumn{4}{|l|}{ Physical activity ${ }^{1}$} \\
\hline $1^{\text {st }}$ third & $262(33.2)$ & $99(31.1)$ & \multirow[t]{3}{*}{0.674} \\
\hline $2^{\text {nd }}$ third & $257(32.6)$ & $112(35.2)$ & \\
\hline $3^{\text {rd }}$ third & $269(34.1)$ & $107(33.6)$ & \\
\hline \multicolumn{4}{|l|}{ Body mass index $\left(\mathrm{Kg} / \mathrm{m}^{2}\right)$} \\
\hline$<25$ & $411(52.4)$ & $178(56.7)$ & \multirow[t]{3}{*}{0.284} \\
\hline $25-29.9$ & $281(35.8)$ & $108(34.4)$ & \\
\hline$\geq 30$ & $92(11.7)$ & $28(8.9)$ & \\
\hline \multicolumn{4}{|l|}{ Blood pressure at baseline $^{2}$} \\
\hline Optimal & $286(35.9)$ & $121(37.5)$ & \multirow[t]{3}{*}{0.043} \\
\hline Normal & $266(33.4)$ & $126(39.0)$ & \\
\hline High normal & $244(30.6)$ & $76(23.5)$ & \\
\hline
\end{tabular}

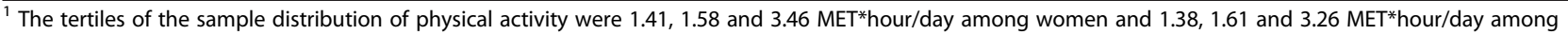
men;

2 Optimal blood pressure was defined as systolic $<120 \mathrm{mmHg}$ and diastolic $<80 \mathrm{mmHg}$, normal blood pressure as systolic $120-129 \mathrm{mmHg}$ or diastolic $80-84$ $\mathrm{mmHg}$ and high normal blood pressure as systolic $130-139 \mathrm{mmHg}$ or diastolic $85-89 \mathrm{mmHg}$. If systolic and diastolic blood pressure readings belonged to different categories, the highest was considered.

stabilized among men while it continued to rise in women (Figure 2). In participants aged below 40 years, the incidence rate was 23.1 (14.2-39.9) per 1000 person-years and 40.0 (23.3-73.9), in women and men, respectively; in those aged 40 to 60 years, the rate was $53.1(42.3-67.4)$ and 62.0 (47.4-82.2), and above age 60 years 110.0 (74.7-165.5) and 64.4 (39.0-110.0), among women and men, respectively. An interaction term between age and sex was statistically significant $(\mathrm{p}=0.032)$.

The incidence rate was similar according to marital status and decreased with increasing educational level $(\geq 13$ years vs. $\leq 4$ years: $R R=0.70,95 \% \mathrm{CI}, 0.46-1.08, \mathrm{p}$ for linear trend $<0.001$ ), independently of age and sex. Overweight and obesity were associated with a 1.67 -fold and 2.44-fold increased risk of hypertension, respectively, independently of age, sex and education. Current smokers and subjects with alcohol intake within the recommended range had a lower incidence rate of hypertension, but the difference was not statistically significant after adjustment for age, sex and educational level (Table 2).

\section{Discussion}

In this urban population the incidence rate of hypertension was almost 50 per 1000 person-years, with new cases occurring predominantly among older subjects, the less educated and those with overweight-obesity. Women had lower risk than men at younger ages and higher risk after age 60 .

This study provides an estimate of the incidence of hypertension in an adult Western European cohort, and 


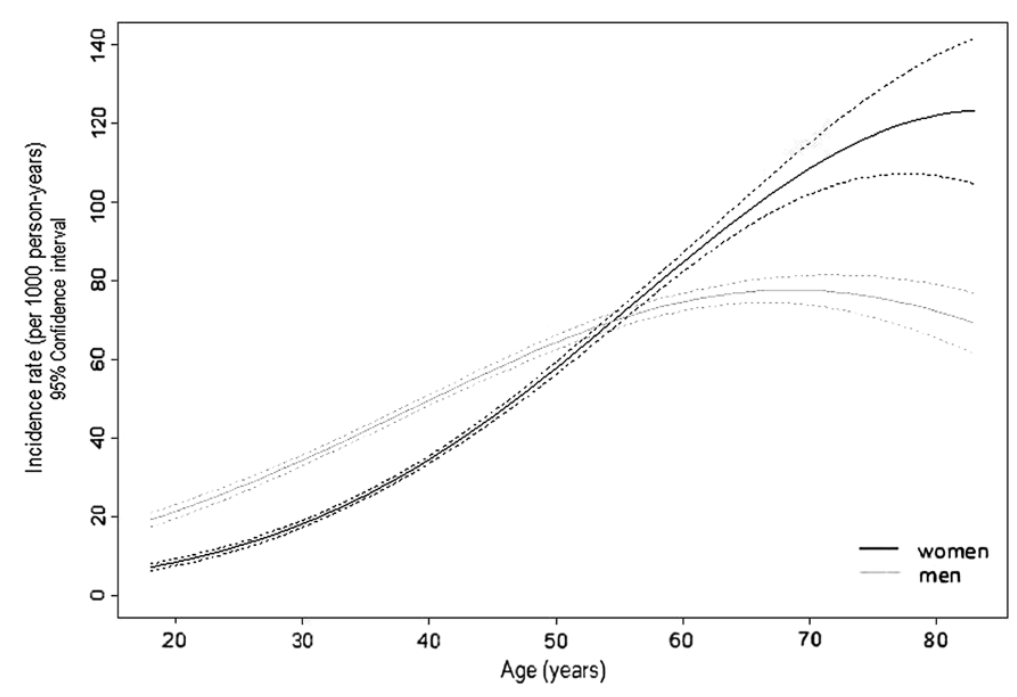

Figure 2 Incidence rate of hypertension according to age and gender.

Table 2 Incidence of hypertension by baseline characteristics of participants

\begin{tabular}{|c|c|c|c|c|}
\hline & Number of new cases & $\begin{array}{l}\text { Incidence rate }(95 \% \mathrm{Cl}) \\
\text { per } 1000 \text { person-years }\end{array}$ & Crude RR $(95 \% \mathrm{Cl})$ & Adjusted RR ${ }^{\mathrm{b}}(95 \% \mathrm{Cl})$ \\
\hline \multicolumn{5}{|l|}{ Education (years) } \\
\hline$\leq 4$ & 70 & $78.2(61.8-99.6)$ & 1 & 1 \\
\hline $4-12$ & 62 & $44.7(34.0-59.8)$ & $0.57(0.40-0.82)$ & $0.76(0.52-1.01)$ \\
\hline$\geq 13$ & 53 & $35.2(26.5-47.8)$ & $0.45(0.31-0.66)$ & $0.70(0.46-1.08)$ \\
\hline \multicolumn{5}{|l|}{ Marital status } \\
\hline Married/civil union & 135 & $52.4(43.6-63.2)$ & 1 & 1 \\
\hline All others & 50 & $37.5(28.0-51.2)$ & $0.72(0.51-1.02)$ & $0.83(0.56-1.22)$ \\
\hline \multicolumn{5}{|l|}{ Tobacco consumption } \\
\hline Current smoker & 43 & $38.0(27.6-53.7)$ & 1 & 1 \\
\hline Ex-smoker & 38 & $51.8(37.1-73.6)$ & $1.36(0.85-2.18)$ & $1.10(0.67-1.79)$ \\
\hline Never-smokers & 104 & $53.4(43.7-65.8)$ & $1.40(0.95-2.07)$ & \\
\hline \multicolumn{5}{|l|}{ Ethanol (g/day) } \\
\hline women: <15.0; men: <30.0 & 111 & $42.8(35.2-52.4)$ & 1 & 1 \\
\hline women: $\geq 15.0 ;$ men: $\geq 30.0$ & 64 & $69.6(53.8-91.1)$ & $1.63(1.17-2.26)$ & $1.23(0.86-1.76)$ \\
\hline \multicolumn{5}{|l|}{ Physical activity ${ }^{a}$} \\
\hline $1^{\text {st }}$ third & 56 & $43.5(33.1-58.1)$ & 1 & 1 \\
\hline $2^{\text {nd }}$ third & 69 & $56.4(43.8-73.6)$ & $1.30(0.89-1.90)$ & $1.18(0.80-1.72)$ \\
\hline $3^{\text {rd }}$ third & 59 & $44.8(34.0-60.1)$ & $1.03(0.69-1.53)$ & $1.05(0.70-1.57)$ \\
\hline \multicolumn{5}{|l|}{ Body mass index $\left(\mathrm{Kg} / \mathrm{m}^{2}\right)$} \\
\hline$<25$ & 64 & $31.2(24.0-41.1)$ & 1 & 1 \\
\hline $25-29.9$ & 87 & $64.0(51.3-80.6)$ & $2.05(1.45-2.91)$ & $1.67(1.17-2.39)$ \\
\hline$\geq 30$ & 33 & $94.1(65.2-138.9)$ & $3.02(1.91-4.76)$ & $2.44(1.50-3.98)$ \\
\hline
\end{tabular}

95\% Cl: 95\% confidence interval.

RR: relative risk.

${ }^{a}$ The tertiles of the sample distribution of physical activity were $1.41,1.58$ and 3.46 MET*hour/day among women and $1.38,1.61$ and 3.26 MET*hour/day among men;

b Adjusted for sex, age, education and an interaction term of age with sex. 
it is the first longitudinal description of the adult population dynamics of the condition in Portugal. Such information will be essential to evaluate the impact of preventive measures and the potential role of changes in major risk factors, as well as to target public health objectives. However, we need to acknowledge certain limitations. Foremost, we had to rely on a relatively small sample size, because a large proportion of the baseline participants were hypertensive, confirming the large burden of high blood pressure in the Portuguese population, and because $27 \%$ of those eligible were lost to follow-up. The latter were significantly younger, less likely to be married or in a civil union, more likely to currently smoke and less likely to have high normal blood pressure when compared with the participants who were followed up. This suggests that the global incidence of hypertension reported is an overestimate of the true incidence in the population because the incidence was higher in older participants, in nonsmokers and in those with high normal blood pressure who are overrepresented in our sample. Since older subjects are more likely to be non-smokers and have high normal blood pressure than the younger, with the weighting of the incidence rate according to the known age structure of the population of Porto, we corrected, at least partially, this overestimation. Additionally, the estimated proportion of adult women in the population of Porto in 2001 was lower than the proportion of women in our sample (56\% in Porto [19] versus 62\% in our sample), and this may have underestimated the overall incidence rate. However, weighting the analyses for sex is expected to have contributed to correct a potential selection bias in our study. Secondly, we measured blood pressure on a single occasion, both at the baseline and follow-up evaluations. Multiple measurements on different days would be a better approach to describe the true blood pressure level. Our methodology might lead to some degree of misclassification resulting in an overestimate of prevalent hypertension at baseline and incident hypertension at follow up, though this is the usual approach in epidemiological studies.

One of the first studies reporting the incidence of hypertension in the general population was the Framingham Heart Study, in 1988. Hypertension incidence per biennium ranged from $3.3 \%$ at ages $30-39$ to $6.2 \%$ at ages $70-79$ in men, and from $1.5 \%$ at ages $30-39$ to $8.6 \%$ at ages 70-79 in women [20]. More recently, in the ARIC study, the incidence of hypertension among whites aged 45 to 64 years at baseline was $37 / 1000$ person-years in women and 40/ 1000 person-years in men [21]. In our sample, the incidence was 63.9/1000 person-years in women and 66.5/1000 person-years in men in the same age range, around $70 \%$ higher than in the ARIC study. In Canada, using administrative data and a validated casedefinition algorithm for hypertension, the age- and sex- adjusted incidence of hypertension was $32.1 / 1000$ personyears in 2004, in participants older than 20 years [22]. In Porto Alegre, Brazil, the age- and sex-specific incidence of objectively defined hypertension in the 1990s was remarkably similar to the estimates we are reporting [23], supporting the external validity of estimates for populations sharing similar characteristics. A Spanish cohort of university graduates aged 25-65 years described a self-reported incidence rate of 8.2/1000 person-years among women, 21.8/1000 person-years among men [24] and an overall cumulative incidence of $5.8 \%$ during 4.4 years of follow-up, from 1999 to 2002 [25], which are certainly underestimates, because they relied on selfreported data. Another study performed in Spain reported estimates based on objectively measured hypertension, in participants aged at least 65 years [26]. In our sample the incidence at this age was approximately $20 \%$ higher than in the Spanish cohort, with a similar pattern of higher risk among women. Hypertension incidence rates from different studies are difficult to compare, because the estimates depend on the criteria for its definition, as well as age, gender and ethnicity composition of the study population, and the length of follow-up. However, in comparison with the estimates presented above, and despite all the described caveats, the incidence of hypertension in Portugal is very high, which is consistent with the high prevalence and high mean blood pressure previously reported in this population, contributing to maintain a high burden of disease at least in the near future [7,27].

In our sample the risk of developing hypertension varied with age, education and BMI at baseline. It is well established that the risk of hypertension depends on modifiable and non-modifiable factors. The increase in blood pressure, and consequently in the incidence of hypertension, with age has long been established, and is largely explained by the primary aging change which occurs in all societies, represented by stiffening and dilation of the proximal aorta [28]. Hypertension is arbitrarily defined by blood pressure thresholds which are reached by the vast majority of the very elderly population [18] and works just as a biomarker of disease that is more accurately described by underlying structural changes.

Like in the Framingham Heart Study [20], we observed that after the 6th decade the incidence in women becomes higher than in men. This pattern could be related with selective removal of men from the population at risk due to prevalent hypertension at baseline and lower survival due to cardiovascular deaths. It is also plausible that menopause could explain this increased risk, since it is associated with a reduction in estradiol and a decrease in estrogen-testosterone ratio, leading to endothelial dysfunction, which is common in postmenopausal women. Another putative mechanism involves sympathetic activation 
and increase in vasoconstriction that will cause hypertension [29]. We could not test to which extent menopause explains the sex-age pattern because this would warrant a relatively large number of both pre- and post-menopausal women within an age range compatible with menopause onset.

The higher incidence rate of hypertension in subjects with less than 4 years of schooling is consistent with those reported in the CARDIA study and the NHANES I Study $[30,31]$ and reflects a clustering of risk factors more prevalent among the less favored people. The transition to political democracy occurring in the seventies in Portugal led to an improvement in economic capital across all social strata, but this increment was proportionally smaller among the lower socioeconomic position groups, resulting in an increasingly unequal society in the economic dimension [32]. Although there is a clear negative association between age and educational level in the Portuguese population belonging to the birth cohorts represented in this sample, the effect of education on hypertension incidence remained strong, despite marginally significant, after adjustment for age.

Blood pressure increases with weight gain, and the increasing prevalence of overweight likely contributes to the high blood pressure levels in all age groups. Fat mass could lead to hypertension by different mechanisms, namely by activating the renin-angiotensin-aldosterone system, increasing sympathetic activity, promoting insulin resistance and leptin resistance and increasing procoagulatory activity and endothelial dysfunction [33]. Our findings strengthen the substantial evidence linking obesity and overweight to the risk of hypertension [34-36].

The specific point estimates of the relative risks suggest that the associations with education, ethanol intake and BMI were stronger at younger ages (data not shown). However, the sample size did not allow us to perform an analysis stratified by age, since there were few new cases before 40 years of age, making all estimates quite unstable. This should be explored in future studies with adequate statistical power for this specific question.

\section{Conclusions}

The annual incidence of hypertension in this adult Portuguese population was high and despite recent progresses in blood pressure related outcomes, the risk of hypertension remains higher in Portugal than in other developed countries. Changing behaviors is an urgent necessity for this population, critical to decrease the incidence of hypertension. Timely and accurate risk factor surveillance could enhance prevention and be used to monitor its effects.

\section{Abbreviations}

95\% Cl: 95\% confidence interval; BMI: Body mass index; MET: Metabolic equivalents; RR: Relative risk.
Competing interests

The authors declare that they have no competing interests.

\section{Authors' contributions}

MP collaborated in the acquisition, analysis and interpretation of the data, and wrote the first draft of the article. NL collaborated in the design of the study and revision of the article. CP collaborated in the design of the study and revision of the article. MS collaborated in the analysis of the data. AA designed the study, analysed and interpreted the data, and reviewed the article critically for important intellectual content. HB designed the study, analysed and interpreted the data, and reviewed the article critically for important intellectual content. All authors have read and approved the final manuscript.

\section{Acknowledgments}

This study was funded by a grant from Laboratórios Menarini and Sociedade Portuguesa de Hipertensão, who had no influence on study design, data collection and analysis, report of results or on the decision to submit the manuscript for publication.

\section{Author details}

${ }^{1}$ Department of Clinical Epidemiology, Predictive Medicine \& Public Health, Institute of Public Health of the University of Porto (ISPUP), University of Porto Medical School, Porto, Portugal. ²Department of Clinical Epidemiology, Predictive Medicine \& Public Health, Institute of Public Health of the University of Porto (ISPUP, University of Porto Medical School, Porto, Portugal. ${ }^{3}$ Department of Internal Medicine, Centro Hospitalar São João, Porto, Portugal. ${ }^{4}$ Department of Clinical Epidemiology, Predictive Medicine \& Public Health, Institute of Public Health of the University of Porto (ISPUP), University of Porto Medical School, Porto, Portugal. ${ }^{5}$ Department of Clinical Epidemiology, Predictive Medicine \& Public Health, Institute of Public Health of the University of Porto (ISPUP), University of Porto Medical School, Porto, Portugal. ${ }^{6}$ Department of Clinical Epidemiology, Predictive Medicine \& Public Health, Institute of Public Health of the University of Porto (ISPUP), University of Porto Medical School, Porto, Portugal.

Received: 22 May 2012 Accepted: 26 November 2012

Published: 28 November 2012

\section{References}

1. World Health Organization: Global health risks: mortality and burden of disease attributable to selected major risks. Geneva: World Health Organization; 2009.

2. Whelton PK: Epidemiology of hypertension. Lancet 1994, 344(8915):101-106

3. Corizzato M, Sega R, Ferrario M, Mancia G, Bianchi C, Fornari C, Perego RA, Cesana G: Possible interaction of environment and genetic factors in workrelated diseases: the case of hypertension. Med Lav 2005, 96(6):467-482.

4. Kunes J, Zicha J: Developmental windows and environment as important factors in the expression of genetic information: a cardiovascular physiologist's view. Clin Sci (Lond) 2006, 111(5):295-305.

5. Vasan RS, Beiser A, Seshadri S, Larson MG, Kannel WB, D'Agostino RB, Levy D: Residual lifetime risk for developing hypertension in middle-aged women and men: The Framingham Heart Study. JAMA 2002, 287(8):1003-1010.

6. Direcção-Geral dos Cuidados de Saúde Primários: Risco de morrer em Portugal 1984. Lisboa: Direcção-Geral dos Cuidados de Saúde Primários; 1987.

7. Macedo ME, Lima MJ, Silva AO, Alcantara P, Ramalhinho V, Carmona J: Prevalence, awareness, treatment and control of hypertension in Portugal: the PAP study. J Hypertens 2005, 23(9):1661-1666.

8. Pereira M, Azevedo A, Barros H: Determinants of awareness, treatment and control of hypertension in a Portuguese population. Rev Port Cardiol 2010, 29(12):1779-1792.

9. Pereira M, Carreira H, Vales C, Rocha V, Azevedo A, Lunet N: Trends in hypertension prevalence (1990-2005) and mean blood pressure (1975-2005) in Portugal: a systematic review. Blood Press 2012, in press.

10. Hajjar I, Kotchen JM, Kotchen TA: Hypertension: trends in prevalence, incidence, and control. Annu Rev Public Health 2006, 27:465-490.

11. Santos AC, Barros H: Prevalence and determinants of obesity in an urban sample of Portuguese adults. Public Health 2003, 117(6):430-437. 
12. Ramos E, Lopes C, Barros H: Investigating the effect of nonparticipation using a population-based case-control study on myocardial infarction. Ann Epidemiol 2004, 14(6):437-441.

13. Krauss RM, Eckel RH, Howard B, Appel LJ, Daniels SR, Deckelbaum RJ Erdman JW Jr, Kris-Etherton P, Goldberg IJ, Kotchen TA, et al: AHA Dietary Guidelines: Revision 2000: A Statement for Healthcare Professionals From the Nutrition Committee of the American Heart Association. Circulation 2000, 102(18):2284-2299.

14. Camões M, Severo M, Santos AC, Barros H, Lopes C: Testing an adaptation of the EPIC Physical Activity Questionnaire in Portuguese adults: A validation study that assesses the seasonal bias of self-report. Ann Hum Biol 2010, 37(2):186-198.

15. Expert Panel on the Identification Evaluation and Treatment of Overweight in Adults: Clinical guidelines on the identification, evaluation and treatment of overweight and obesity in adults: executive summary. Am J Clin Nutr 1998, 68:899-917.

16. Perloff D, Grim C, Flack J, Frohlich ED, Hill M, McDonald M, Morgenstern BZ: Human blood pressure determination by sphygmomanometry. Circulation 1993, 88:2460-2470.

17. Mancia G, De Backer G, Dominiczak A, Cifkova R, Fagard R, Germano G, Grassi G, Heagerty AM, Kjeldsen SE, Laurent S, et al: 2007 ESH-ESC Practice Guidelines for the Management of Arterial Hypertension: ESH-ESC Task Force on the Management of Arterial Hypertension. J Hypertens 2007, 25(9):1751-1762

18. Chobanian AV, Bakris GL, Black HR, Cushman WC, Green LA, Izzo JL Jr, Jones DW, Materson BJ, Oparil S, Wright JT Jr, et al: The Seventh Report of the Joint National Committee on Prevention, Detection, Evaluation, and Treatment of High Blood Pressure: the JNC 7 report. JAMA 2003, 289(19):2560-2572.

19. Instituto Nacional de Estatística: População residente (N. $)^{\circ}$ por Local de residência (à data dos Censos 2001), Sexo e Grupo etário; Decenal; 2012. http://www.ine.pt.

20. Dannenberg AL, Garrison RJ, Kannel WB: Incidence of hypertension in the Framingham Study. Am J Public Health 1988, 78(6):676-679.

21. Diez Roux AV, Chambless L, Merkin SS, Arnett D, Eigenbrodt M, Nieto FJ, Szklo M, Sorlie P: Socioeconomic disadvantage and change in blood pressure associated with aging. Circulation 2002, 106(6):703-710.

22. Tu K, Chen Z, Lipscombe LL: Prevalence and incidence of hypertension from 1995 to 2005: a population-based study. CMAJ 2008, 178(11):1429-1435.

23. Moreira LB, Fuchs SC, Wiehe M, Gus M, Moraes RS, Fuchs FD: Incidence of hypertension in Porto Alegre, Brazil: a population-based study. J Hum Hypertens 2008, 22(1):48-50.

24. Beunza JJ, Martinez-Gonzalez MA, Serrano-Martinez M, Alonso A: Incidence of hypertension in a cohort of Spanish university graduates: the SUN study. Rev Esp Cardiol 2006, 59(12):1331-1334.

25. Pimenta AM, Beunza JJ, Bes-Rastrollo M, Alonso A, Lopez CN, VelasquezMelendez G, Martinez-Gonzalez MA: Work hours and incidence of hypertension among Spanish university graduates: the Seguimiento Universidad de Navarra prospective cohort. J Hypertens 2009, 27(1):34-40.

26. Gutierrez-Misis A, Sanchez-Santos MT, Banegas JR, Zunzunegui MV, Castell $M V$, Otero A: Prevalence and incidence of hypertension in a population cohort of people aged 65 years or older in Spain. J Hypertens 2011, 29(10):1863-1870.

27. Danaei G, Finucane MM, Lin JK, Singh GM, Paciorek CJ, Cowan MJ, Farzadfar F, Stevens GA, Lim SS, Riley LM, et al: National, regional, and global trends in systolic blood pressure since 1980: systematic analysis of health examination surveys and epidemiological studies with 786 country-years and 5.4 million participants. Lancet 2011, 377(9765):568-577.

28. O'Rourke MF, Hashimoto J: Mechanical factors in arterial aging: a clinical perspective. J Am Coll Cardiol 2007, 50(1):1-13

29. Coylewright M, Reckelhoff JF, Ouyang P: Menopause and hypertension: an age-old debate. Hypertension 2008, 51(4):952-959.

30. Dyer AR, Liu K, Walsh M, Kiefe C, Jacobs DR Jr, Bild DE: Ten-year incidence of elevated blood pressure and its predictors: the CARDIA study. Coronary Artery Risk Development in (Young) Adults. J Hum Hypertens 1999, 13(1):13-21.

31. Ford ES, Cooper RS: Risk factors for hypertension in a national cohort study. Hypertension 1991, 18(5):598-606.

32. Barreto A: Social Change in Portugal: 1960-2000. New York: Columbia University Press; 2003.
33. Lamounier-Zepter $V$, Bornstein SR, Ehrhart-Bornstein M: Mechanisms of obesity-related hypertension. Horm Metab Res 2004, 36(6):376-380.

34. Parikh NI, Pencina MJ, Wang TJ, Benjamin EJ, Lanier KJ, Levy D, D'Agostino RB Sr, Kannel WB, Vasan RS: A risk score for predicting near-term incidence of hypertension: the Framingham Heart Study. Ann Intern Med 2008, 148(2):102-110.

35. Vasan RS, Larson MG, Leip EP, Kannel WB, Levy D: Assessment of frequency of progression to hypertension in non-hypertensive participants in the Framingham Heart Study: a cohort study. Lancet 2001, 358(9294):1682-1686.

36. Stamler J: Epidemiologic findings on body mass and blood pressure in adults. Ann Epidemiol 1991, 1(4):347-362.

doi:10.1186/1471-2261-12-114

Cite this article as: Pereira et al.: Incidence of hypertension in a prospective cohort study of adults from Porto, Portugal. BMC Cardiovascular Disorders 2012 12:114

\section{Submit your next manuscript to BioMed Central and take full advantage of:}

- Convenient online submission

- Thorough peer review

- No space constraints or color figure charges

- Immediate publication on acceptance

- Inclusion in PubMed, CAS, Scopus and Google Scholar

- Research which is freely available for redistribution 